Paidéia, 2001, 11(20), 99-102

\title{
RELACIONAMENTO INTERPESSOAL EM ENFERMAGEM: CONSIDERAÇÕES SOBRE FORMAÇÃO/ATUAÇÃO NO NÍVEL MÉDIO DE ENFERMAGEM ${ }^{1}$
}

\author{
Maria Inês Lemos Coelho Ribeiro \\ Luiz Jorge Pedrão ${ }^{2}$ \\ EERP-Universidade de São Paulo
}

\begin{abstract}
RESUMO: Trata-se de uma reflexão sobre o tema, relacionamento interpessoal nos cursos e na atuação profissional de auxiliares e técnicos de enfermagem. Constata-se que os pedidos dos pacientes se situam na esfera relacional e raramente na técnica e que o relacionamento interpessoal aparece como mola propulsora do cuidado. Sabe-se que $70 \%$ da mão de obra de enfermagem é desenvolvida por profissionais de nível médio, sendo executores de grande parte das técnicas, justificando assim este estudo. Considerou-se imprescindível que o profissional citado tenha um melhor preparo no tema em questão para oferecer uma assistência mais humanizada. Cabe às instituições formadoras de nível médio proporcionarem condições para o desenvolvimento desta habilidade e ao enfermeiro assistencial mantê-la, principalmente através de atividades educativas contínuas em serviço.
\end{abstract}

Palavras Chave: relacionamento interpessoal, ensino de enfermagem.

\section{INTERPERSONAL RELATIONSHIP IN NURSING: CONSIDERATIONS ON THE EDUCATION/PRACTICE OF VOCATIONAL NURSES}

ABSTRACT: This is a reflection concerning interpersonal relationships in nursing programs and in the professional practice of nursing auxiliaries and nursing aides. It is verified that patients' requests are found in the relational sphere and rarely in the technical one. Interpersonal relationships appear as the driving incentive of health care. It is known that $70 \%$ of nursing labor is developed by vocational nursing professionals who perform a large number of procedures, which justifies this study. That the mentioned professionals should have a better preparation concerning the theme in question in order to provide more humanized care was considered to be essential. Vocational Nursing schools are obliged to provide the necessary conditions for the development of such skill and the clinical nurse is responsible for keeping it, especially by means of continual educational activities at work.

Key words: interpersonal relationship, nursing teaching.

O presente texto trata-se de uma reflexão sobre o relacionamento interpessoal no nível médio de enfermagem e a sua importância no desenvolvimento das ações assistenciais, usando como metodologia uma descrição sobre a revisão literária disponível.

Nas últimas décadas, vimos̉ surgir na literatura de enfermagem vários trabalhos salientando a

\footnotetext{
${ }^{1}$ Artigo recebido para publicação em. agosto de 2001; aceito em fevereiro de 2002.

2 Endereço para correspondência: Luiz Jorge Pedrão, Departamento de Enfermagem Psiquiátrica e Ciências Humanas, Escola de Enfermagem de Ribeirão Preto, USP, Av. Bandeirantes, 3900, Monte Alegre, Ribeirão Preto, SP, Cep 14040-902, e-mail lujope@eerp.usp.br
}

importância do relacionamento interpessoal na assistência ao paciente. Nas décadas de 60 e 70 foram feitas algumas tentativas para humanizar esta assistência, tratando o indivíduo como um todo, incluindo aspectos biológicos, sociais e espirituais, e criticando a objetificação do paciente (Waldow, 1998).

Na prática de enfermagem, verificamos que toda assistência ao indivíduo se processa por meio das relações interpessoais (Gattás, 1984). Observamos que a enfermeira, profissional com alta competência técnica, responsável pela gerência do serviço e administração do pessoal, ainda não está dando a 
devida importância às relações interpessoais de sua equipe e à orientação e supervisão desse pessoal.

Inicialmente, o tema parece bastante rotineiro, familiar, no nosso campo de atuação. No entanto, o relacionamento interpessoal merece maior atenção devido à sua complexidade, já que lidamos com relação entre pessoas, cada uma com suas características e personalidades diferentes.

Furegato (1999) descreve que o relacionamento enfermeiro-paciente é uma relação entre duas ou mais pessoas, entre o profissional e a pessoa que requer ajuda, que se dá através do processo terapêutico (início, desenvolvimento e final) objetivando a resolução da crise.

Para Travelbee (1982), toda assistência ao paciente-cliente deveria se dar através das interações entre duas pessoas: uma que precisa de ajuda e outra que proporciona ajuda. Segundo esta autora é o enfermeiro que se une ao paciente-cliente para ajudálo a revelar e compreender sua experiência e, a partir daí, desenvolver um relacionamento. $O$ relacionamento enfermeiro-paciente é meta a ser atingida, é função específica da enfermeira, é a interação planejada com objetivos definidos entre duas pessoas, na qual ambas modificam seu comportamento, construtivamente, com a evolução do processo de relacionamento.

O paciente é uma pessoa, um ser humano único que no momento requer nossa ajuda. $O$ enfermeiro é uma pessoa, um ser humano único, que adquiriu conhecimentos e habilidades específicas para cuidar dos outros e dispõe-se a isso. Através da comunicação interpessoal, ambos poderão atingir seus objetivos.

Sadala \& Stefanelli (1996) citam que a comunicação é vista na enfermagem como instrumento básico, como uma competência e uma habilidade que precisam ser desenvolvidas, praticadas após terem passado por um aprendizado teórico do relacionamento. Observa-se as dificuldades de ensino e aprendizagem nesta técnica no nível médio de enfermagem, cujo ensino é mais elementar que o da graduação nesta profissão (Simpósio, 1990). Acreditamos também que exista dificuldade em abordar este tema, o que entendemos que possa impedir a valorização dessa temática. Consideramos a comunicação como parte integrante do cuidar, portanto é um instrumento de trabalho do enfermeiro e de sua equipe, que precisa ser pesquisado para que seus resultados possam contribuir para os avanços esperados no campo da assistência à saúde.

Sabe-se que cabe à enfermeira e às instituições formadoras proporcionarem condições para o desenvolvimento das habilidades e atitudes específicas, possibilitando aos profissionais de nível médio de enfermagem às suas ações serem terapêuticas através do relacionamento interpessoal (Miranda, Rodrigues \& Scatena, 1996).

\section{Justificativa}

Atualmente observa-se uma predominância na formação dos profissionais de enfermagem no aspecto instrumental, em detrimento do expressivo, designações estas utilizadas por Waldow (1998). A enfermagem no Brasil, não muito diferente de outros países, passou a desvalorizar o cuidado humano, atendendo-se a uma ideologia de cura. As ações curativas ocupam a maior parte das atividades, utilizando-se tecnologias cada vez mais sofisticadas.

A enfermagem é exercida por profissionais com formação universitária que são os enfermeiros, e por profissionais de nível médio, que são os técnicos e auxiliares de enfermagem. Aos enfermeiros tem cabido a esfera do saber e, ao pessoal de nível médio, o fazer ...

A educação de grau médio constitui tema de estudos educacionais em enfermagem, porém ainda é muito discreta esta preocupação, pois existem dificuldades em encontrar material bibliográfico neste assunto, que constitui $24,4 \%$ dos estudos publicados no período de 1980 a 1992, referindo-se aos cursos de graduação, conforme dados de Miron (1994). Em nossa proposta de fazer uma reflexão sobre o relacionamento interpessoal, verificamos a ausência total de publicações do tema sobre os cursos de nível médio de enfermagem.

Os enfermeiros entendem que os trabalhadores de nível médio, oriundos em sua grande maioria de classes sociais menos favorecidas, recebem o mínimo necessário para executar tarefas (Senaden, 1994). Constata-se assim uma contradição na divisão de trabalho da enfermagem, pois se prega sempre maior e melhor qualidade de assistência e quem 
executa é o menos qualificado, sendo isto facilmente comprovado através dos dados fornecidos pelo Conselho Federal de Enfermagem (COFEn), de maio de 2001, que mostram um número de 90.661 enfermeiros existentes no país, formados em 139 escolas de enfermagem, para um número de 102.897 técnicos de enfermagem e 451.911 auxiliares de enfermagem.

Acreditamos que os alunos de nível médio de enfermagem devem pensar, agir, criticar e buscar melhor capacitação profissional, e que dentre as funções da escola, uma é preparar o aluno para procedimentos técnicos e outra é participar da formação do cidadão, pois o ensino deve ser visto pelo indivíduo como um facilitador da sua inserção na sociedade, como profissional competente, que sabe priorizar cuidados, percebendo o paciente/cliente como um todo, respeitando o seu "momento" e a sua "individualidade" (Fernandes \& cols., 1999).

O enfermeiro deve preparar sua equipe para que todos atuem dentro da mesma linha de conduta com o paciente. Orientá-los e supervisioná-los como seres humanos, de maneira compreensiva e responsável, é um modo de ensiná-los como tratar o paciente. Se o enfermeiro valoriza a atenção individual e o respeito às necessidades do paciente, certamente instruirá seu pessoal neste sentido e valorizará as comunicações de cada um sobre suas impressões e preocupações com o estado do paciente (Furegato,1999).

As ações de cuidar propiciam que cuidadores e pacientes interajam. Esta interação parece tornarse cada vez mais impessoal, breve e formal. Muitas vezes os procedimentos realizados ocorrem de forma mecanizada e rotinizada, sendo comum o fato de muitos profissionais não saberem como iniciar uma conversação e como mantê-la de forma criativa e adequada.

Seja qual for a área de trabalho, temos constatado que os pedidos formulados pelos nossos doentes se situam na esfera relacional. Assim, entendemos que quaisquer que sejam as condições em que se desenvolve a prestação de cuidados, as nossas posturas profissionais devem ocorrer com o propósito central de promover, fomentar e manter aos usuários de nossos serviços os direitos inerentes às pessoas. Em última análise, oferecer cuidados efetivos apenas do ponto de vista técnico, sem prestar atenção à pessoa, além de constituir uma negação do respeito que lhe assiste, é prova de insuficiência na prestação de cuidados de qualidade.

Furegato (1999) escreve que tem-se percebido que os enfermeiros de várias especialidades, originários de diferentes recantos do país, estão buscando algo mais do que simplesmente a execução de tarefas para atender às exigências de suas unidades. Eles querem mais: querem tratar o paciente como ser humano e querem ser reconhecidos como seres humanos que ajudam os necessitados a terem uma vida melhor, apesar da doença ou do transtorno apresentado no momento.

A mesma autora afirma que estando o enfermeiro interessado em humanizar o cuidado, não importando a área de atuação, procurará instrumentalizar-se para orientar suas próprias ações assim como as de sua equipe de serviço.

Sabemos que o caminho para a humanização da assistência é longo, pois requer mudança pessoal no modo de encarar a doença e o doente, melhor qualificação profissional, ensino mais seguro, supervisão por profissional qualificado, e outros fatores. Entretanto, acreditamos que estamos contribuindo para que alguns profissionais repensem seus valores, suas atitudes e alguns identificando-se com estes princípios façam alguma coisa para humanizar a assistência. A enfermagem é uma profissão humanista em seus princípios básicos. Seu discurso é humanista, embora muitas vezes, o profissicnal encontre-se agindo contra seus princípios profissionais mais elevados.

\section{Considerações Finais}

Considerando a preocupação com a formação do nivel médio na habilidade de relacionar-se, $e$ após essas reflexões abordadas neste trabalho, seria importante, então, despertar nos docentes de ensino médio e também nos profissionais de enfermagem de modo geral um interesse em atentar para a habilidade de relacionar-se com o paciente.

A profissão de enfermagem, partindo de um relacionamento flexivel e democrático, promoverá saúde mental, estimulando o desenvolvimento de personalidades sadias, substituindo práticas tradi- 
cionais que impedem o desempenho, como a velhae rígida disciplina, o tratamento frio e formal, por um relacionamento mais participante, mais humano. Enfim, urge que as variáveis relevantes e de controle no relacionamento enfermeiro-paciente sejam trabalhadas com mais atenção, porque é através do próprio relacionamento que podemos promover a saúde mental das pessoas (Manzolli, 1983).

Ressaltamos a importância de instrumentalizar o profissional de nível médio, sob a orientação e supervisão do enfermeiro, para incrementar sua formação e atuação no que tange às habilidades das relações interpessoais e do aperfeiçoamento técnico, favorecendo assim, a eficiência da assistência de enfermagem ao paciente e sua competência profissional. Esperamos que essas reflexões sejam o início de uma maior conscientização destes profissionais para capacitar o nível médio de enfermagem no desenvolvimento da habilidade de relacionamento interpessoal.

\section{Referências Bibliográficas}

Fernandes, M.F.P. et al. (1999). Caracterização do perfil dos alunos de nível médio- auxiliares de enfermagem. Nursing, 9, 17-21.

Furegato, A.R.F. (1999). Relações interpessoais terapêuticas na enfermagem. Ribeirão Preto, São Paulo: Scala.

Gattás, M.L.B. (1984). Relacionamento Interpessoal enfermeiro-paciente. Rev. Paulista de Enfermagem, 4, n.2, 59-61.

Manzolli, M.C. (1983). Relacionamento em Enfermagem. Aspectos psicológicos. São Paulo: Sarvier.

Miranda, F.A.N.; Rodrigues, A.R.F.; \& Scatena, M.C.M. (1996). Relacionamento interpessoal focalizando o elemento surpresa numa interação. Nursing, n.101, p. 30-34, 1996.

Miron, V.L. (1994). A produção dos enfermeiros sobre ensino médio de enfermagem no Brasil. Ribeirão Preto. Tese de Doutorado, Universidade de São Paulo, Ribeirão Preto, SP.

Sadala, M.L.A. \& Stefanelli, M.C. (1996). Avalia- ção do ensino de relacionamento enfermeirapaciente. Rev. Latino-americana,4, 139-51.

SENADEN-Seminário Nacional de Diretrizes para Educação em Enfermagem no Brasil (1994). A formação dos trabalhadores em nivel médio de enfermagem (pp.13,16). Rio de Janeiro: UERJ, p.13-16.

Simpósio Brasileiro de Comunicação em Enfermagem (1990). Resumo: Conferência. Ribeirão Preto, p. 599-609.

Travelbee, J. (1982). Intervencion en enfermería psiquiátrica. Colômbia: Carvajal.

Waldow, V.R. (1998). Cuidado humano. O resgate necessário. Porto Alegre: Sagra Luzzato. 